\title{
Spontaneous Aneurysm of External Carotid Artery: Management and Complications
}

\author{
Pankaj Banode ${ }^{1}$ Abhinav A. Mohan ${ }^{1}$ Shishir Ravekar ${ }^{1}$ \\ ${ }^{1}$ Department of Intervention Radiology, Jawaharlal Nehru Medical \\ College, Sawangi, Wardha, Maharashtra, India \\ 2Department of Periodontics, Sharad Pawar Dental College, \\ Sawangi, Maharashtra, India
}

\author{
Address for correspondence Pankaj Banode, DMRD, DNB, \\ Department of Intervention Radiology, JN Medical College, Sawangi, \\ Wardha 442005, Maharashtra, India (e-mail: drpjbanode@gmail.com).
}

Int J Recent Surg Med Sci 2018;4:81-84

\author{
Abstract \\ Keywords \\ - extracranial carotid \\ artery aneurysm \\ - common carotid \\ artery \\ - respiratory \\ obstruction
}

Extracranial carotid artery aneurysm is a rare vascular disease in the neck with variable presentation. Aneurysms are associated with significant mortality and morbidity and are associated with fatal complication secondary to spontaneous rupture or tracheal compression or laryngeal edema and distal embolization. A 43-year-old male patient presented with large aneurysm arising from proximal common carotid artery (CCA) causing tracheal obstruction leading to life-threatening respiratory symptoms. The endovascular interventional management is an emerging alternative for surgical option and providing promising results with almost similar safety and efficacy. Endovascular management of an extracranial carotid artery aneurysm using stent graft is minimally invasive and effective.

\section{Introduction}

Extracranial carotid artery aneurysm is a rare vascular disease in the neck, with occurrence of approximately 0.4 to $4 \%$ of all peripheral vascular aneurysm..$^{1-3}$ The presentation of aneurysm is may vary from neurologic or visual deficit secondary to emboli to pain over the course of the carotid artery, asymptomatic pulsatile swelling in the neck, and respiratory obstruction symptoms. ${ }^{4}$ Aneurysm in the neck is classified into dissecting, traumatic, iatrogenic, dysplastic, and mycotic aneurysm..$^{5-7}$ Aneurysms are associated with significant mortality and morbidity, and are associated with fatal complication secondary to spontaneous rupture or tracheal compression or laryngeal edema and distal embolization. ${ }^{4,8}$ The treatment options for aneurysm of extracranial carotid artery are surgical procedures or endovascular interventional management, which is an emerging alternative for surgical option and providing promising results with almost similar safety and efficacy. ${ }^{9,10}$

\section{Case History}

A 43-year-old male patient with respiratory obstruction presented in emergency department. On examination, there was large swelling in the neck in anterior triangle on left side compressing the trachea leading to severe respiratory obstruction and stridor. Tracheostomy was per-

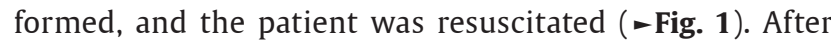
stabilizing the patient, ultrasonography (USG) and Doppler study were performed, which revealed large aneurysm arising from the left proximal carotid artery displacing the carotid vessel posteriorly and the defect was not well visualized. As there were no significant atherosclerotic changes and no clinical history of trauma, diagnosis of spontaneous aneurysm of the extracranial carotid artery was made. To evaluate the extent and neck of aneurysm, three-dimensional (3D) computed tomographic (CT) angiography was performed (-Fig. 2), which revealed large aneurysm arising from the proximal common carotid artery (CCA) located anterior to the CCA with the neck of aneurysm being located anteromedially. Aneurysm is extending across the midline compressing the trachea toward right side. The carotid vessels are compressed posterolaterally by aneurysm. Aneurysm is measuring approximately $4.4 \times 2.3 \times 3.8 \mathrm{~cm}$ in size, and the defect is measuring approximately $8 \mathrm{~mm}$. In view of difficult location, large size of aneurysm, and posterior location of defect, the patient was refereed to interventional radiology department for endovascular treatment option.

Using right femoral access with $6 \mathrm{~F}$ sheath under all aseptic precaution, initial left carotid angiography was performed, which revealed large aneurysm arising from the
Update Society
License terms

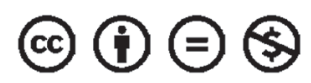




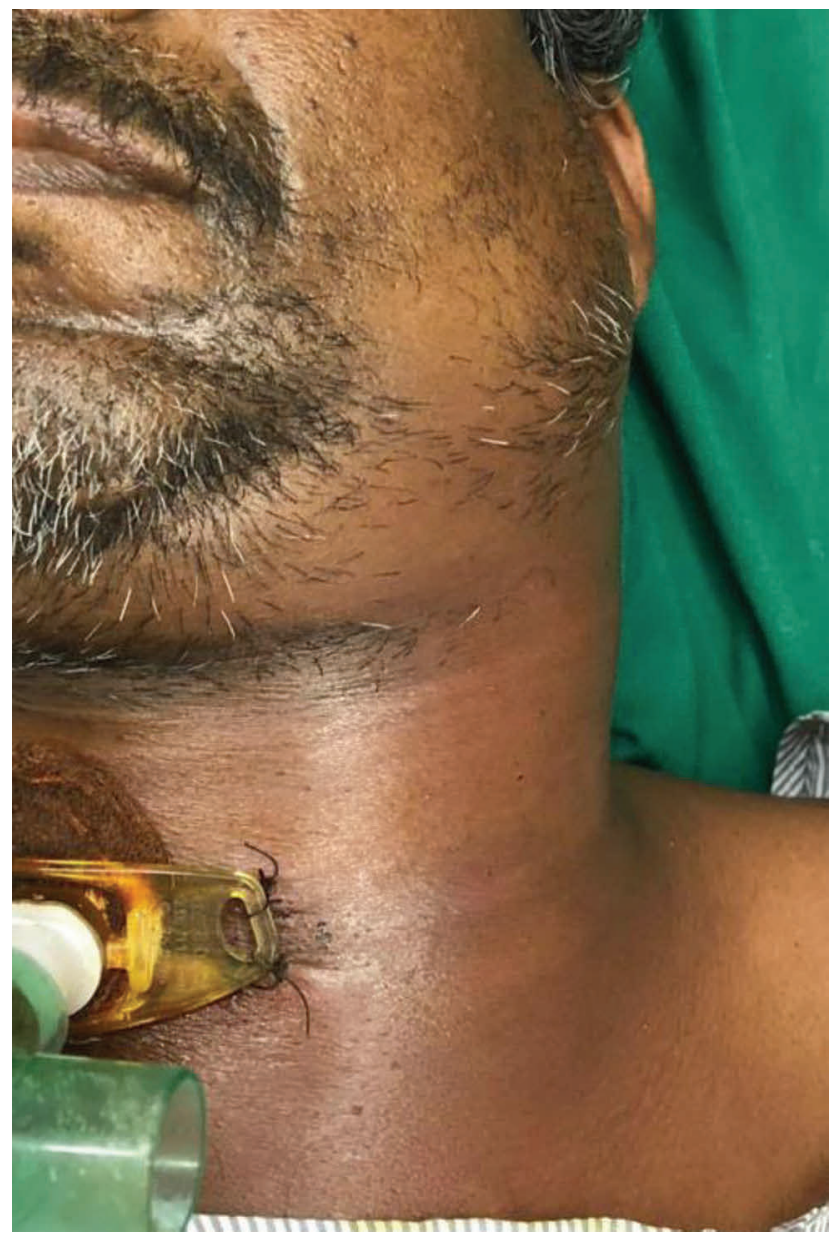

Fig. 1 Swelling in neck on left side with tracheostomy tube in situ.

left CCA with anteromedially pointing neck that measures approximately 6 to $7 \mathrm{~mm}$ in width. Using 0.035 hydrophilic wire, the wire is negotiated across the defect and access to the external carotid artery was achieved distal to aneurysm over which Amplatz stiff wire was exchanged. Over the stiff wire, $9 \mathrm{~F}$ long sheath $(70 \mathrm{~cm}$ Cook) was introduced beyond the neck of aneurysm with the help of roadmap. Stent graft of $10 \mathrm{~mm} \times 40 \mathrm{~mm}$ (fluency, Bard) was implanted across the neck in the left proximal carotid artery under fluoroscopic and roadmap guidance and after conforming the position on preimplantation digital subtraction angiogram (-Fig. 3). Post-stenting balloon angioplasty was performed using $8-\times 40-\mathrm{mm}$ balloon. Post-stenting angiogram reveals good flow in the extra- and intracranial carotid artery and in the intracranial circulation (-Fig. 4). There was no flow in aneurysm post-stenting without any endoleaks. The patient was given bolus dose of ticagrelor (180 mg) bolus dose on table before stenting and 5,000 IU heparin during procedure to maintain activated clotting time (ACT) between 200 and 250. After stenting, sheath was removed and compression was done manually. The patient was given injectable antibiotic for 3 days followed by oral antibiotic for total 7 days. Postprocedure immediate

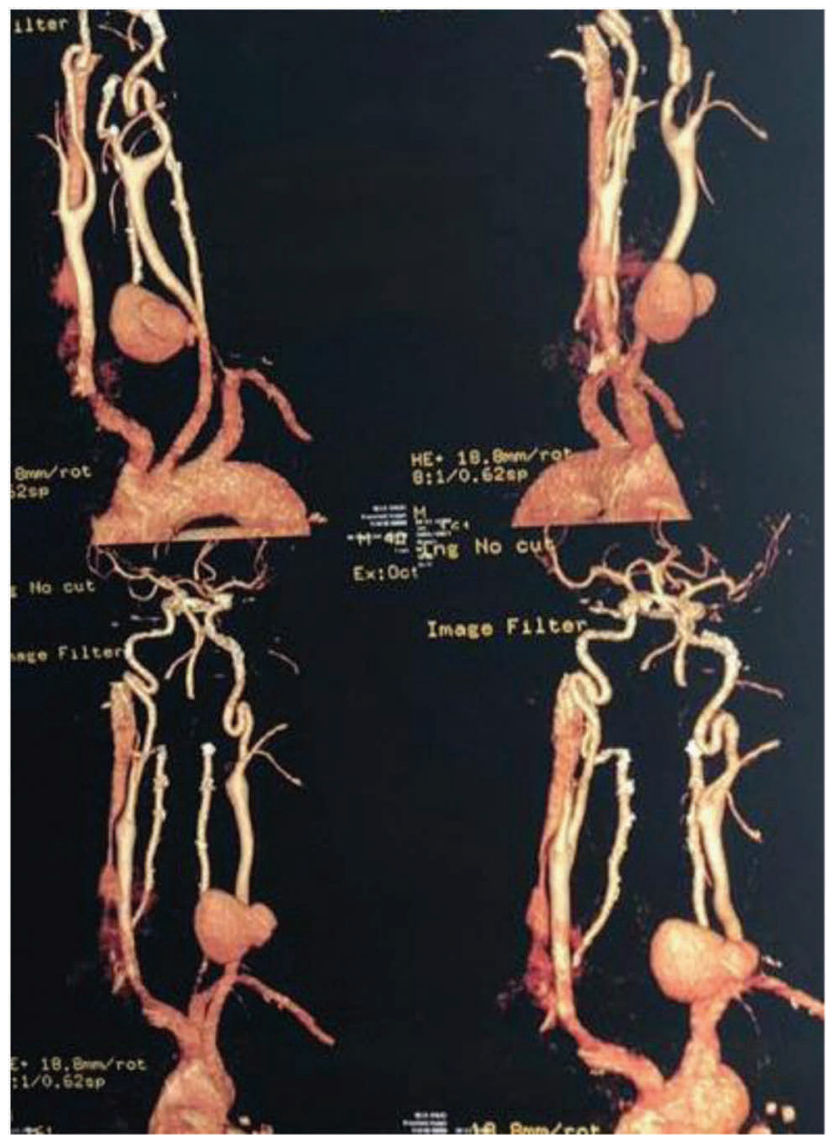

Fig. 2 CT angiogram 3D VRT (volume rendering technique) images reveal large aneurysm arising from proximal common carotid artery (CCA).

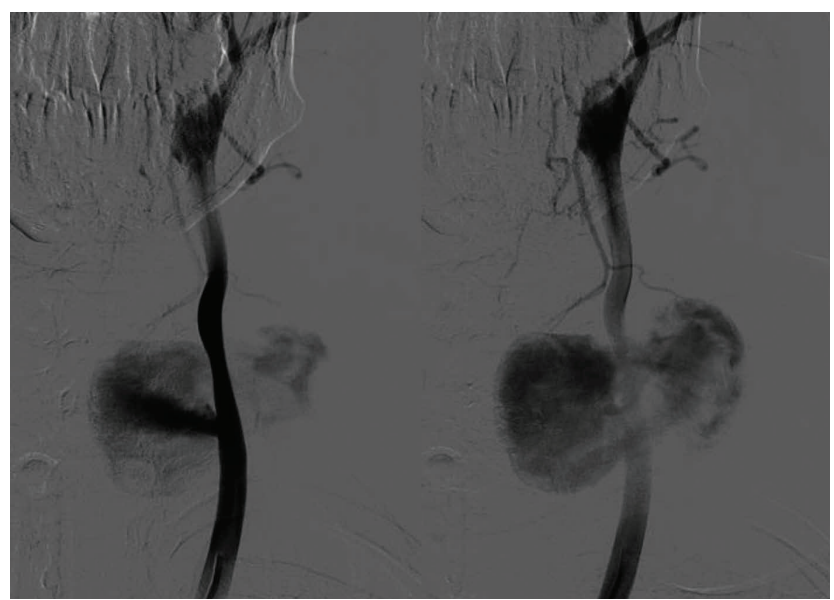

Fig. 3 Digital subtraction angiography reveals large aneurysm arising from proximal common carotid artery (CCA) located anteromedially displacing and compressing proximal CCA.

Doppler shows thrombus formation in aneurysm with fluid-fluid level.

A 48-hour follow-up shows significant regression in size of the swelling and regression in compression over the trachea. Tracheostomy tube was removed after 5 days, and the patient was discharged with good outcome. 


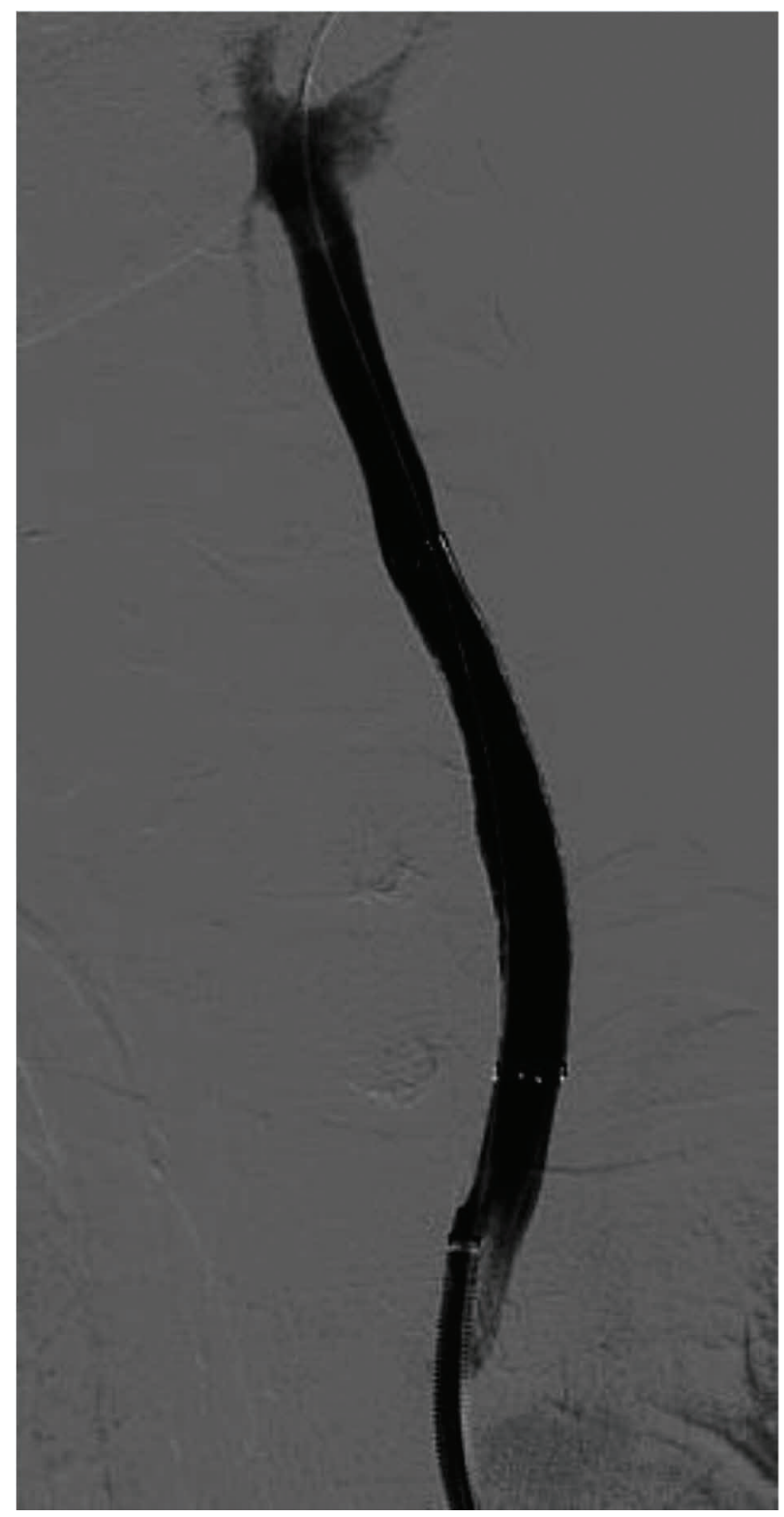

Fig. 4 Post-stent grafting images show no flow in aneurysm with good flow in common carotid artery (CCA) and internal carotid artery (ICA).

\section{Discussion}

Extracranial carotid artery aneurysm is uncommon with most patients presenting with asymptomatic pulsatile neck mass. Respiratory obstructive symptom is a rare presentation of extracranial carotid artery aneurysm. The other presentation of aneurysm is neurologic or visual deficit and pain over the course of the carotid artery. Aneurysms are associated with significant mortality and morbidity and with fatal complication secondary to rupture or tracheal compression or laryngeal edema and neurologic morbidity secondary to distal embolization. According to etiology, aneurysms are classified into atherosclerotic, mycotic dissecting, and posttraumatic aneurysm. The other classification of aneurysm in the neck depends on shape as dissecting, fusiform, saccular, and pseudoaneurysm. Ultrasonography and Doppler are usually the initial screening and diagnostic modalities to confirm the diagnosis with limitation in demonstrating the defect, extension, and relation of aneurysm with the carotid vessel. The 3D CT angiography and magnetic resonance angiography play an important role in evaluating the relation of aneurysm with the carotid vessel and the defect, thereby helping in planning the treatment of aneurysm.

The treatment options for aneurysm of the extracranial carotid artery are surgical procedures or endovascular interventional management such as resection with end-to-end anastomosis or grafting, internal carotid artery ligation, or extra- to intracranial bypass open surgery. The other emerging alternative for surgical option is endovascular interventional management, which provides promising results with almost similar safety and efficacy. The endovascular stenting is a minimally invasive procedure, thereby avoiding general anesthesia. It is technically feasible with high procedure success and relatively lower complication rate (cranial nerve deficit associated with operative procedure). The endovascular procedures are also not limited by location of aneurysm.

\section{Conclusion}

We report a case of an extracranial carotid artery aneurysm presented with severe tracheal compression and demonstrate that the use of covered stent graft is minimally invasive and effective.

\section{Conflict of Interest}

None.

\section{References}

1 Kaouel K, Mechergui S, Ben Mrad I, et al. Traitement chirurgical des anévrismes carotidiens extracrâniens: à propos de dix cas. J Mal Vasc 2012;37(4):201-206

2 Hosoda K, Fujita S, Kawaguchi T, Shibata Y, Tamaki N. The use of an external-internal shunt in the treatment of extracranial internal carotid artery saccular aneurysms: technical case report. Surg Neurol 1999;52(2):153-155

3 Hertzer NR. Extracranial carotid aneurysms: a new look at an old problem. J Vasc Surg 2000;31(4):823-825

4 Rosset E, Albertini JN, Magnan PE, Ede B, Thomassin JM, Branchereau A. Surgical treatment of extracranial internal carotid artery aneurysms. J Vasc Surg 2000;31(4):713-723

5 Tabata M, Kitagawa T, Saito T, et al. Extracranial carotid aneurysm in Takayasu's arteritis. J Vasc Surg 2001;34(4):739-742

6 Smith BL, Munschauer CE, Diamond N, Rivera F. Ruptured internal carotid aneurysm resulting from neurofibromatosis: treatment with intraluminal stent graft. J Vasc Surg 2000;32(4):824-828

7 McCann RL. Basic data related to peripheral artery aneurysms. Ann Vasc Surg 1990;4(4):411-414 
84 Spontaneous Aneurysm of External Carotid Artery Banode et al.

8 Szopinski P, Ciostek P, Kielar M, Myrcha P, Pleban E, Noszczyk W. A series of 15 patients with extracranial carotid artery aneurysms: surgical and endovascular treatment. Eur J Vasc Endovasc Surg 2005;29(3):256-261

9 Zhou W, Lin PH, Bush RL, et al. Carotid artery aneurysm: evolution of management over two decades. J Vasc Surg 2006;43(3):493-496, discussion 497
10 Srivastava SD, Eagleton MJ, O'Hara P, Kashyap VS, Sarac T, Clair D. Surgical repair of carotid artery aneurysms: a 10-year, single-center experience. Ann Vasc Surg 2010;24(1):100-105 